\title{
Participation in physical activity and back pain among an elderly population in South Asia
}

\author{
Ghose Bishwajit ${ }^{1,2}$ \\ Shangfeng Tang' \\ Sanni Yaya ${ }^{3}$ \\ Zhanchun Feng'
}

'School of Medicine and Health Management, Tongji Medical College, Huazhong University of Science and Technology, Wuhan, Hubei, People's Republic of China; Institute of Nutrition and Food Science, University of Dhaka, Dhaka, Bangladesh; ${ }^{3}$ School of International Development and Global Studies, University of Ottawa, Ottawa, ON, Canada
Correspondence: Zhanchun Feng School of Medicine and Health Management, Tongji Medical College, 13 Hangkong Lu, Hankou, 430030. Wuhan, Hubei, People's Republic of China Tel +86278369273I

Email zcfeng@hust.edu.cn
This article was published in the following Dove Press journal: Journal of Pain Research

15 April 2017

Number of times this article has been viewed

Introduction: Globally, chronic back pain is one of the most commonly encountered medical conditions among an elderly population with significant bearings on health, functional mobility and general well-being.

Objective: To estimate the burden of chronic back pain and its association with physical activity (PA) among population aged 50 years and above in Bangladesh, India, Nepal, Pakistan and Sri Lanka.

Methods: Cross-sectional data on 8502 men and women aged 50 years and above were collected from the World Health Survey (2002). Three forms of PA were considered - vigorous physical activity (VPA), moderate physical activity (MPA) and walking. Odds ratios (ORs) of the association between self-reported back pain and VPA, MPA and walking were calculated by using generalized estimating equations.

Results: The prevalence of back pain was, respectively, $64.8 \%, 19.8 \%, 69.5 \%, 40.6 \%$ and $36.2 \%$ in Bangladesh, India, Nepal, Pakistan and Sri Lanka. No significant association between back pain and VPA was observed among men in any of the countries. In India, Pakistan and Sri Lanka, the odds of suffering from back pain were, respectively, 29\%, 2.5 times and 59\% higher among women who almost never took MPA. In India, taking MPA for few days a week and almost never was associated with, respectively, 38\% (OR $=1.38 ; 95 \%$ confidence interval $[\mathrm{CI}]=1.017-1.876)$ and $56 \%(\mathrm{OR}=1.564 ; 95 \% \mathrm{CI}=1.003-2.438)$ higher odds of reporting back pain. Walking almost never was also associated with, respectively, 83\% (OR=1.829; 95\% $\mathrm{CI}=1.14-2.934)$ and 2.9 times $(\mathrm{OR}=2.854 ; 95 \% \mathrm{CI}=1.419-5.738)$ higher odds of reporting back pain among men in Nepal and Pakistan, respectively.

Conclusion: Though the relationship was not consistent across sex and countries, results indicate that inadequate or nonparticipation can substantially increase the likelihood of suffering from back pain among an elderly population in this region. Further research is needed to better understand this relationship and the potential of exercised-based strategies to prevent and treat back pain among elderly persons.

Keywords: back pain, older people, physical activity, South Asia, world health survey

\section{Introduction}

Worldwide, chronic musculoskeletal pain is one of the most challenging health conditions encountered by the elderly population and health practitioners. Back pain, being the most common of all musculoskeletal conditions, has a lifetime prevalence of $\sim 60 \%-80 \%$ among adult population in the Western countries. ${ }^{1}$ In the global Burden of Disease 2010 Study, low back pain (LBP) was reported to cause more global disability than any other condition (out of 291 conditions). ${ }^{2}$ In the UK, LBP affects 
around one-third of the adult population each year of whom about one-fifth will consult their general practitioners (GPs) about their back pain. ${ }^{3}$ However, currently there is insufficient evidence to know whether or not LBP is a result of aging, and if there is any etiological differences between LBP during early and late stages of life. Findings from review studies have suggested that the prevalence of LBP increases linearly from the third decade of life until the 60 years of age. ${ }^{4,17}$ Thus, with the expanding proportion of elderly population the burden of LBP is likely to increase in the coming decades and has the potential for causing significant challenges for primary health care service systems especially in the developing countries.

LBP is a major health problem among the elderly not only because of the high prevalence, but also because of the adverse impacts on functional mobility, activities of daily living, sleep quality, psychological symptoms and reduced health-related quality of life (HRQoL). ${ }^{5-7}$ Apart from the health-related issues, back pain has been shown to be associated with increased medical expenditure, workplace absenteeism and early retirement, ${ }^{8,9}$ which altogether can have serious impacts of socioeconomic well-being at individual and community level. The etiology of back pain is multifarious; however, the common causes ranges from injuries and mechanical problems, such as intervertebral disk degeneration, vertebral fractures, herniated disks and myofascial pain. ${ }^{10}$ Given the diverse nature of the problem, LBP is managed by various health care providers, such as GP, family practitioners, neurologists, rheumatologists, emergency physicians, and orthopedic and neurological surgeons. ${ }^{11}$ Appropriate prevention and management strategies starting at the primary care level hold the potential to reduce the prevalence of population living with chronic back pain, for which a wide variety of cause-specific treatment and therapeutic options are available. A balanced approach by considering patients overall physical and psychological factors are believed to be most effective for effective management of LBP. ${ }^{10,16,17}$

With the increasing understanding of the beneficial effects of exercise on physical and mental health, HRQoL, and almost any aspects of health, there has been a growing interest on the exercise-directed therapy for the management of chronic back pain. There is now a convincing body of medical literature demonstrating that increased levels of obesity and sedentary lifestyle will increase the prevalence of conditions associated with chronic pain, ${ }^{12}$ and have underscored the importance of remaining physically active as long periods of inactivity will adversely affect recovery from the pain. ${ }^{14-16}$ Exercise can serve as a useful therapeutic tool to increase functional capacity, preventing the pain becoming chronic, and even reduce the risk of future back injuries. ${ }^{18}$ However, as nearly all of the evidence on the health effects of exercise on back pain are gathered from studies conducted in developed countries, there is currently limited knowledge in the context of developing countries. Regional differences in the patterns of back pain and the distribution of lifestyle related risk factors are necessary to develop a broader understanding of the problem and designing effective intervention strategies. In view of this, we conducted this study in selected South Asian countries where the demography is characterized by a predominantly younger population, however, aging is increasingly being recognized as a public health issue. Therefore, research and policy interventions for age-related chronic diseases has been gathering momentum. Although the surveys were conducted quite some time ago, the findings of this study might be useful for both future researchers and practitioners in the management of back pain among the middle-aged to elderly population.

\section{Methods \\ Data collection}

Nationally representative population surveys on physical activity (PA) patterns are rare in South Asia. Therefore, for this study we collected secondary datasets from the 2002 World Health Survey (WHS) which was implemented in 70 countries between January and December 2002. Sampling methods have been published in prior studies based on WHS datasets. ${ }^{19}$ The surveys were cross-sectional in nature and covered a broad range of health (mental health, chronic diseases) and behavioral (PA, smoking, drinking, fruits and vegetable consumption) risk factors among male and female adults aged $\geq 18$ years. ${ }^{19}$ The health module in the WHS surveys was closely synchronized with the International Classification of Functioning, Disability and Health. ${ }^{20}$

\section{Variable}

Outcome variable for this study was self-reported status of back pain. Inclusion criteria was age being $\geq 50$ years, and exclusion criteria was absence of information on PA status. Participants were asked - have you experienced back pain (including disc problems) during the last 30 days? To which they could answer: Yes or No.

Main explanatory variables were PA which were measured across three different areas: vigorous physical activity (VPA), moderate physical activity (MPA) and walking. For VPA, participants were asked:

Now, think about all the vigorous activities which take hard physical effort that you did in the last 7 days. Vigorous 
activities make you breathe much harder than normal and may include heavy lifting, digging, aerobics, or fast bicycling. Think only about those physical activities that you did for at least 10 minutes at a time. During the last 7 days, on how many days did you do vigorous physical activities?

Similarly, for MPA participants were asked:

Now think about activities which take moderate physical effort that you did in the last 7 days. MPA make you breathe somewhat harder than normal and may include carrying light loads, bicycling at a regular pace, or doubles tennis. Do not include walking. Again, think about only those physical activities that you did for at least 10 minutes at a time. During the last 7 days, on how many days did you do moderate physical activities?

For Walking, participants were asked:

Now think about the time you spent walking in the last 7 days. This includes at work and at home, walking to travel from place to place, and any other walking that you might do solely for recreation, sport, exercise, or leisure. During the last 7 days, on how many days did you walk for at least 10 minutes at a time?

Currently, the standards for measuring the amount of PA remains inconsistent across studies as different researchers employ various levels of measurement, such as total hours of PA per day, number of days per week or month. Besides that, the recommended amount of PA are expected to vary for different age groups and physical conditions. Hence, categorization of the amount of PA as "adequate" and "inadequate" would not be appropriate. For this study, we collapsed the number of days into three groups for all three types of PA as: $0-1$ day= almost never, $2-4$ days $=$ few days/ week and 5-7 days $=$ almost/everyday. The trichotomization was done in light of insights from current literature on the minimum amount of PA that is likely to have any effect on health outcomes. We also considered several covariates for the purpose of adjusting for potential confounders as guided by the previous researches - age: 50-59, 60-69, 70-79, $>80$ years; sex: female, male; current marital status: unmarried, married; educational attainment: no formal schooling, less than primary school, primary school completed, secondary school completed, high school completed, preuniversity/ university completed; current job: government employee, nongovernment employee, self-employed, unemployed/other; currently smoke: daily, not daily, not at all; ever drank alcohol: yes, no. ${ }^{8-11,16,20,24,31,34}$

\section{Data analysis}

All analyses were conducted with SPSS 21 for Mac (SPSS Inc., Chicago, IL, USA). Initial checks were performed for missing values, outliers and multicollinearity issues. Basic sociodemographic characteristics of the participants were presented as frequencies and percentages. Contingency table was generated for chi-square tests to check any statistical association between back pain and the explanatory variables. The variables that were found significant at $p<0.25$ in contingency tables were retained for the multivariable regression analysis. The results of regression analysis were presented as odds ratios (ORs) and corresponding 95\% confidence intervals (CI). All tests were two-tailed, and statistical significance was set at $p<0.05$. Following the main regression analysis, we reran the analysis two more times with different classifications of PA for sensitivity check (first with 0-3 and 4-7 days, and then as $0,1-2,3-4,>4$ days). However the results did not show any significant variation from those of the main analysis (results not shown).

\section{Ethical review}

WHS survey protocols were approved by ethics review board of the World Health Organization (WHO). Therefore, any additional ethical review of the study was not necessary because it was based on anonymous publicly available dataset with no identifiable information of the participants.

\section{Results \\ Descriptive analysis}

Basic population characteristics were presented in Table 1. Most of the participants were in the youngest age group of 50-59 years. In all countries, most of the participants were male (except in Sri Lanka), and were currently married. Literacy rate was highest in Sri Lanka (89.6\%) and lowest in Nepal (16\%). Rate of university-level qualification was highest in Sri Lanka, and in the rest of the countries most of the participants had less than primary or primarylevel qualification. More than half of the participants were unemployed or not worked for payment. In Bangladesh and Nepal, more than half of the participants reported smoking on daily basis. Prevalence of nonsmokers were highest in Sri Lanka (72.4\%), and lowest in Nepal (42.3\%), and that of ever drinking alcohol was highest in Nepal (39.9\%) and lowest in Bangladesh (4.2\%). Regarding participating in PA, almost one-third of the participants in India (33.8\%) and more than a quarter in Sri Lanka (27.9\%) reported engaging in VPA almost every day. However, that of engaging in MPA was highest in Nepal followed by India and Sri Lanka. 
Table I Sociodemographic characteristics of the study population, WHS 2002-2003

\begin{tabular}{|c|c|c|c|c|c|}
\hline Variables & $\begin{array}{l}\text { Bangladesh, } \\
N=1189\end{array}$ & $\begin{array}{l}\text { India, } \\
N=2233\end{array}$ & $\begin{array}{l}\text { Nepal, } \\
N=2039\end{array}$ & $\begin{array}{l}\text { Pakistan, } \\
N=1304\end{array}$ & $\begin{array}{l}\text { Sri Lanka, } \\
N=1737\end{array}$ \\
\hline Age (years), mean (SD) & $61.15(9.5)$ & $60.19(9.91)$ & $60.14(9.17)$ & $60(96)$ & $60.2(9.15)$ \\
\hline $50-59$ & 48.5 & 47.7 & 47.3 & 51.0 & 54.4 \\
\hline $60-69$ & 30.7 & 33.9 & 31.7 & 28.5 & 27.3 \\
\hline 70-79 & 15.1 & 14.4 & 16.5 & 14.1 & 14.6 \\
\hline$\geq 80$ & 5.7 & 3.9 & 4.5 & 6.4 & 3.6 \\
\hline \multicolumn{6}{|l|}{ Sex } \\
\hline Female & 48.4 & 49.4 & 49.3 & 41.0 & 52.3 \\
\hline Male & 51.6 & 50.6 & 50.7 & 59.0 & 47.7 \\
\hline \multicolumn{6}{|l|}{ Current marital status } \\
\hline Unmarried & 31.1 & 26.8 & 27.6 & 21.2 & 30.0 \\
\hline Married & 68.9 & 73.2 & 72.4 & 78.8 & 70.0 \\
\hline \multicolumn{6}{|l|}{ Educational attainment } \\
\hline No formal schooling & 59.0 & 53.8 & 84.0 & 71.1 & 10.4 \\
\hline Less than primary school & 16.2 & 11.9 & 6.8 & 5.3 & 10.2 \\
\hline Primary school completed & 13.3 & 12.7 & 4.5 & 8.5 & 34.5 \\
\hline Secondary school completed & 5.5 & 9.2 & 3.3 & 6.4 & 33.4 \\
\hline High school completed & 2.4 & 5.2 & 0.7 & 3.6 & 9.2 \\
\hline Preuniversity/university completed & 3.6 & 7.1 & 0.7 & 5.1 & 2.2 \\
\hline \multicolumn{6}{|l|}{ Current job } \\
\hline Government employee & 2.8 & 5.2 & 1.9 & 5.0 & 22.0 \\
\hline Nongovernment employee & 3.8 & 6.2 & 0.6 & 6.5 & 6.8 \\
\hline Self-employed & 38.6 & 33.5 & 56.6 & 31.0 & 19.6 \\
\hline Unemployed/other & 54.8 & 55.1 & 40.9 & 57.5 & 51.6 \\
\hline \multicolumn{6}{|l|}{ Currently smoke } \\
\hline Daily & 52.1 & 42.7 & 51.5 & 26.1 & 19.2 \\
\hline Not daily & 4.6 & 3.2 & 6.2 & 3.4 & 8.5 \\
\hline Not at all & 43.3 & 54.1 & 42.3 & 70.6 & 72.4 \\
\hline \multicolumn{6}{|l|}{ Ever drank alcohol } \\
\hline Yes & 4.2 & 11.6 & 39.9 & 12.0 & 22.0 \\
\hline No & 95.8 & 88.4 & 60.1 & 88.0 & 78.0 \\
\hline \multicolumn{6}{|l|}{ VPA } \\
\hline Almost never & 69.6 & 57.8 & 69.2 & 82.0 & 58.1 \\
\hline Few days/week & 13.1 & 9.4 & 11.5 & 5.7 & 14.0 \\
\hline Almost everyday & 17.3 & 32.8 & 19.3 & 12.3 & 27.9 \\
\hline \multicolumn{6}{|l|}{ MPA } \\
\hline Almost never & 43.3 & 29.2 & 26.1 & 64.9 & 29.3 \\
\hline Few days/week & 21.8 & 11.6 & 9.1 & 9.4 & 17.7 \\
\hline Almost everyday & 34.9 & 59.2 & 64.8 & 25.8 & 53.0 \\
\hline \multicolumn{6}{|l|}{ Walking } \\
\hline Almost never & 27.6 & 19.8 & 21.6 & 18.8 & 16.1 \\
\hline Few days/week & 19.6 & 11.2 & 13.3 & 13.0 & 16.3 \\
\hline Almost everyday & 52.8 & 69.1 & 65.0 & 68.2 & 67.6 \\
\hline
\end{tabular}

Abbreviations: VPA, vigorous physical activity; MPA, moderate physical activity; SD, standard deviation; WHS, World Health Survey.

Level of PA was lowest in Pakistan as $82 \%$ and $64.9 \%$ of the participants reported almost never engaging in VPA and MPA, respectively. Compared to VPA and MPA, the rate of walking was relatively high in all the countries with about two-third (except in Bangladesh, 52.8\%) of the participants reported going for walk almost every day.

\section{Prevalence of back pain}

Contingency table (Table 2) was generated to calculate the prevalence of back pain across the categories of the explanatory variables. The prevalence of back pain was, respectively, $64.8 \%, 19.8 \%, 69.5 \%, 40.6 \%$ and $36.2 \%$ in Bangladesh, India, Nepal, Pakistan and Sri Lanka. Results indicate that in most of the countries the likelihood of reporting back pain was higher among participants who were female, aged 50-59 years, were currently married (except in Nepal), had no formal education (except in Sri Lanka) and had no job and walked almost never (in all countries). Back pain was associated with lack of VPA in all the countries but Bangladesh and Nepal, and with MPA in all the countries but Pakistan. 
Table 2 Percentage of sample population reporting back pain in last 30 days, WHS 2002-2003

\begin{tabular}{|c|c|c|c|c|c|}
\hline Variables & $\begin{array}{l}\text { Bangladesh } \\
(64.8 \%)\end{array}$ & $\begin{array}{l}\text { India } \\
\text { (I9.8\%) }\end{array}$ & $\begin{array}{l}\text { Nepal } \\
(69.5 \%)\end{array}$ & $\begin{array}{l}\text { Pakistan } \\
(40.6 \%)\end{array}$ & $\begin{array}{l}\text { Sri Lanka } \\
(36.2 \%)\end{array}$ \\
\hline \multicolumn{6}{|l|}{ Age (years) } \\
\hline $50-59$ & 45.5 & 45.2 & 45.5 & 46.3 & 43.3 \\
\hline $60-69$ & 30.6 & 34.7 & 32.1 & 28.9 & 31.5 \\
\hline 70-79 & 17.1 & 15.4 & 18.1 & 17.2 & 18.5 \\
\hline$>80$ & 6.8 & 4.7 & 4.4 & 7.6 & 6.7 \\
\hline$p$-value & 0.002 & 0.06 & 0.014 & 0.009 & $<0.001$ \\
\hline \multicolumn{6}{|l|}{ Sex } \\
\hline Female & 57.1 & 57.5 & 53.7 & 50.5 & 63.9 \\
\hline Male & 42.9 & 42.5 & 46.3 & 49.5 & 36.1 \\
\hline$p$-value & $<0.001$ & $<0.001$ & $<0.001$ & $<0.001$ & $<0.001$ \\
\hline \multicolumn{6}{|l|}{ Current marital status } \\
\hline Unmarried & 36.8 & 30 & 28.4 & 24.8 & 36.5 \\
\hline Married & 63.2 & 70 & 71.6 & 75.2 & 63.5 \\
\hline$p$-value & $<0.001$ & 0.001 & 0.119 & 0.006 & $<0.001$ \\
\hline \multicolumn{6}{|l|}{ Educational attainment } \\
\hline No formal schooling & 64.4 & 63.4 & 86.5 & 80.2 & 16.4 \\
\hline Less than primary school & 16.9 & 12.5 & 6.1 & 3.4 & 10.4 \\
\hline Primary school completed & 12.1 & 12.2 & 3.9 & 7.8 & 36.6 \\
\hline Secondary school completed & 3.6 & 6.1 & 2.3 & 3.6 & 29.8 \\
\hline High school completed & 1.2 & 2.3 & 0.6 & 2.3 & 5.6 \\
\hline Preuniversity/university completed & 1.8 & 3.5 & 0.6 & 2.8 & 1.3 \\
\hline$p$-value & $<0.001$ & $<0.001$ & $<0.001$ & $<0.001$ & $<0.001$ \\
\hline \multicolumn{6}{|l|}{ Current job } \\
\hline Government employee & 1.4 & 2.5 & 1.8 & 1.5 & 23.6 \\
\hline Nongovernment employee & 2.7 & 5.8 & 0.3 & 6.6 & 3.5 \\
\hline Self-employed & 35.2 & 31.0 & 55.5 & 24.4 & 14.5 \\
\hline Unemployed/other & 60.6 & 60.7 & 42.4 & 67.5 & 58.4 \\
\hline$p$-value & $<0.001$ & $<0.001$ & 0.005 & $<0.001$ & $<0.001$ \\
\hline \multicolumn{6}{|l|}{ Currently smoke } \\
\hline Daily & 41.0 & 52.2 & 41.7 & 73.5 & 76.1 \\
\hline Not daily & 3.6 & 2.9 & 5.9 & 4.2 & 7.2 \\
\hline Not at all & 55.3 & 44.9 & 52.4 & 22.3 & 16.7 \\
\hline$p$-value & 0.003 & 0.134 & 0.462 & 0.022 & 0.631 \\
\hline \multicolumn{6}{|l|}{ Ever drank alcohol } \\
\hline Yes & 4.3 & 11.9 & 40.0 & 9.5 & 18.0 \\
\hline No & 95.7 & 88.1 & 60.0 & 90.5 & 82.0 \\
\hline$p$-value & 0.491 & 0.318 & 0.484 & 0.31 & 0.001 \\
\hline \multicolumn{6}{|l|}{ VPA } \\
\hline Almost never & 69.6 & 58.3 & 70.0 & 88.1 & 66.9 \\
\hline Few days/week & 12.6 & 9.4 & 11.6 & 2.3 & 13.1 \\
\hline Almost everyday & 17.8 & 32.3 & 18.5 & 9.6 & 20.1 \\
\hline$p$-value & 0.294 & 0.04 & 0.386 & $<0.001$ & $<0.001$ \\
\hline \multicolumn{6}{|l|}{ MPA } \\
\hline Almost never & 45.7 & 31.7 & 26.2 & 69.4 & 36.6 \\
\hline Few days/week & 21.3 & 12.9 & 9.3 & 6.2 & 16.2 \\
\hline Almost everyday & 33.0 & 55.4 & 64.5 & 24.4 & 47.1 \\
\hline$p$-value & 0.066 & 0.003 & 0.127 & 0.002 & $<0.001$ \\
\hline \multicolumn{6}{|l|}{ Walking } \\
\hline Almost never & 48.6 & 65.6 & 58.5 & 66.7 & 63.5 \\
\hline Few days/week & 20.6 & 12.5 & 15.5 & 11.3 & 16.9 \\
\hline Almost everyday & 30.8 & 21.9 & 26.0 & 21.9 & 19.6 \\
\hline$p$-value & $<0.001$ & 0.004 & $<0.001$ & 0.032 & 0.006 \\
\hline
\end{tabular}

Notes: $p$-values calculated from chi-square tests.

Abbreviations: VPA, vigorous physical activity; MPA, moderate physical activity; WHS, World Health Survey. 


\section{Multivariable analysis}

Results of multivariable analysis on the association between back pain and different forms of PA among women and men were presented in Tables 3 and 4, respectively. Reference category for all three types of PA (VPA, MPA and walking) was almost every day. Table 4 indicates that in Pakistani women who almost never engaged in VPA had 3.7 times (adjusted odds ratio $[\mathrm{AOR}]=3.72 ; 95 \% \mathrm{CI}=1.095-12.63$ ) higher, and in Sri Lankan women who engaged in VPA few days a week had $62 \%(\mathrm{AOR}=1.619 ; 95 \% \mathrm{CI}=1.122-2.337)$ higher odds of reporting back pain compared to those who engaged almost every day. In India, Pakistan and Sri Lanka, the odds of suffering from back pain were, respectively, $29 \%$, 2.5 times and 59\% higher among women who almost never took MPA. Significant association between back pain and walking was observed among women in India only, and the odds were $26 \%(\mathrm{OR}=1.26 ; 95 \% \mathrm{CI}=1.003-1.584)$ and $33 \%$
$(\mathrm{OR}=1.326 ; 95 \% \mathrm{CI}=1.008-1.746)$ higher for walking few days and walking almost never, respectively.

No significant association between back pain and VPA was observed among men in any of the countries. In India, taking MPA for few days a week and almost never was associated with, respectively, 38\% (OR=1.38; 95\% $\mathrm{CI}=1.017-1.876)$ and 56\% $(\mathrm{OR}=1.564 ; 95 \% \mathrm{CI}=1.003-2.438)$ higher odds of reporting back pain. Walking almost never was also associated with, respectively, 83\% (OR=1.829; 95\% $\mathrm{CI}=1.14-2.934)$ and 2.9 times $(\mathrm{OR}=2.854$; 95\% CI=1.419-5.738) higher odds of reporting back pain among men in Nepal and Pakistan, respectively.

\section{Discussion}

This study reports the prevalence of back pain and of three forms of PA including VPA, MPA and walking among subjects aged $\geq 50$ years in Bangladesh, India, Nepal, Pakistan and Sri Lanka. The findings suggest a high burden of back

Table 3 Association between back pain and engaging in exercise among women in South Asia, WHS 2002-2003

\begin{tabular}{|c|c|c|c|c|c|}
\hline $\begin{array}{l}\text { Type of physical } \\
\text { activity }\end{array}$ & $\begin{array}{l}\text { Bangladesh, OR } \\
(95 \% \mathrm{Cl})\end{array}$ & $\begin{array}{l}\text { India, OR } \\
(95 \% \mathrm{CI})\end{array}$ & $\begin{array}{l}\text { Nepal, OR } \\
(95 \% \mathrm{Cl})\end{array}$ & $\begin{array}{l}\text { Pakistan, OR } \\
(95 \% \mathrm{Cl})\end{array}$ & $\begin{array}{l}\text { Sri Lanka, OR } \\
(95 \% \mathrm{Cl})\end{array}$ \\
\hline \multicolumn{6}{|l|}{ VPA } \\
\hline Almost everyday & Ref & Ref & Ref & Ref & Ref \\
\hline Few days/week & $1.406(0.755-2.616)$ & $0.888(0.725-1.087)$ & $0.349(0.878-1.127)$ & $0.512(0.250-1.048)$ & $1.619 *(1.122-2.337)$ \\
\hline Almost never & $1.123(0.485-2.600)$ & $0.900(0.653-1.24 I)$ & $0.548(0.782-1.115)$ & $3.720 *(1.095-12.63)$ & $1.36 \mid(0.799-2.316)$ \\
\hline \multicolumn{6}{|l|}{ MPA } \\
\hline Almost everyday & Ref & Ref & Ref & Ref & Ref \\
\hline Few days/week & $0.759(0.479-1.202)$ & $1.360 *(1.029-1.799)$ & $0.948(0.989-0.698)$ & $1.767(0.763-4.092)$ & $0.917(0.619-1.361)$ \\
\hline Almost never & $0.861(0.482-1.538)$ & $1.286 *(1.038-1.593)$ & $0.673(0.95 \mathrm{I}-0.755)$ & $2.494 *(I .448-4.294)$ & $1.584 *(1.159-2.165)$ \\
\hline \multicolumn{6}{|l|}{ Walking } \\
\hline Almost everyday & Ref & Ref & Ref & Ref & Ref \\
\hline Few days/week & $0.893(0.565-1.410)$ & $1.260 *(1.003-1.584)$ & $0.901(0.680-1.318)$ & $0.783(0.523-I .17 I)$ & $1.095(0.765-1.566)$ \\
\hline Almost never & $0.930(0.542-1.595)$ & $1.326 *(1.008-1.746)$ & $0.682(0.189-1.595)$ & $0.606(0.366-1.002)$ & $0.86 \mid(0.605-1.226)$ \\
\hline
\end{tabular}

Notes: Models adjusted for age, marital status, educational qualification, job category for all countries, and additionally for smoking in Bangladesh and Pakistan, and for drinking in Sri Lanka. *Indicates statistically significant associations.

Abbreviations: $\mathrm{Cl}$, confidence interval; MPA, moderate physical activity; OR, odds ratio; VPA, vigorous physical activity; WHS, World Health Survey.

Table 4 Association between back pain and engaging in exercise among men in South Asia, WHS 2002-2003

\begin{tabular}{|c|c|c|c|c|c|}
\hline $\begin{array}{l}\text { Type of physical } \\
\text { activity }\end{array}$ & $\begin{array}{l}\text { Bangladesh, OR } \\
(95 \% \mathrm{Cl})\end{array}$ & $\begin{array}{l}\text { India, OR } \\
(95 \% \mathrm{Cl})\end{array}$ & $\begin{array}{l}\text { Nepal, OR } \\
(95 \% \mathrm{Cl})\end{array}$ & $\begin{array}{l}\text { Pakistan, OR } \\
(95 \% \mathrm{Cl})\end{array}$ & $\begin{array}{l}\text { Sri Lanka, OR } \\
(95 \% \mathrm{Cl})\end{array}$ \\
\hline \multicolumn{6}{|l|}{ VPA } \\
\hline Almost everyday & Ref & Ref & Ref & Ref & Ref \\
\hline Few days/week & $1.4(0.935-2.098)$ & $0.764(0.567-1.028)$ & I.I 76 (0.782-I.768) & $0.682(0.4 \mid 3-1.126)$ & $1.369(0.958-1.957)$ \\
\hline Almost never & $1.420(0.826-2.442)$ & $0.752(0.452-\mid .25 I)$ & I.02I (0.57I-I.826) & 1.331 (0.523-3.387) & $1.391(0.886-2.185)$ \\
\hline \multicolumn{6}{|l|}{ MPA } \\
\hline Almost everyday & Ref & Ref & Ref & Ref & Ref \\
\hline Few days/week & $0.7 \mid I(0.485-1.043)$ & $1.381 *(1.017-1.876)$ & $1.352(0.934-1.956)$ & $0.673(0.455-0.996)$ & $1.406(0.975-2.026)$ \\
\hline Almost never & $0.774(0.506-1.183)$ & $1.564 *(1.003-2.438)$ & I.24I (0.674-2.283) & $1.328(0.664-2.656)$ & I.I $68(0.774-1.76 I)$ \\
\hline \multicolumn{6}{|l|}{ Walking } \\
\hline Almost everyday & Ref & Ref & Ref & Ref & Ref \\
\hline Few days/week & 0.805 (0.499-I.298) & $1.246(0.9 \mid 4-1.699)$ & 1.359 (0.963-1.917) & I.086 (0.684-I.724) & $1.281(0.835-1.965)$ \\
\hline Almost never & $0.78 \mid(0.509-1.199)$ & $\mathrm{I} .428(0.96 \mathrm{I}-2.122)$ & $1.829 *(1.140-2.934)$ & $2.854 *(1.419-5.738)$ & $\mathrm{I} . \mathrm{I} 27(0.70 \mathrm{I}-\mathrm{I} .8 \mathrm{I} 5)$ \\
\hline
\end{tabular}

Notes: Models adjusted for age, marital status, educational qualification, job category for all countries, and additionally for smoking in Bangladesh and Pakistan, and for drinking in Sri Lanka. *Indicates statistically significant associations.

Abbreviations: $\mathrm{Cl}$, confidence interval; MPA, moderate physical activity; OR, odds ratio; VPA, vigorous physical activity; WHS, World Health Survey. 
pain especially in Bangladesh and Nepal where more than three-fifth of the participants reported having back pain. In all five countries, participants who reported back pain were aged between 50 and 59 years, and the prevalence was also higher among women compared to men. From the analysis, it is difficult to make any assumption regarding this variation; however, these two findings are consistent with those from a recently published systematic review which found that the prevalence increases linearly until the 60 years of age, and are more prevalent in women. ${ }^{4}$ Of note, the prevalence of back pain in Nepal was more than threefold than that of India. This is perhaps because the rate of current employment was also highest in Nepal which is associated with higher likelihood of experiencing back pain. A follow-up study in Western Nepal reported that LBP was higher among subjects involved in agriculture and heavy weight lifting. ${ }^{23}$ Similar evidence were reported by WHO estimates which found that $\sim 37 \%$ of all LBP is of occupational origin. ${ }^{24}$ Considerable differences were observed among the countries in terms of PA patterns as well. Rate of participation in VPA almost every day and few days a week was highest in India and in Bangladesh, respectively, whereas that of participation in MPA almost every day and few days a week was highest in Nepal and in Bangladesh, respectively. Rate of nonparticipation in both VPA and MPA was highest in Pakistan.

Previous nationally representative statistics on back pain and PA are not available. However, at subnational level, and among different age groups the prevalence was reported to be $23 \%$ among adults of working age in rural North India, ${ }^{25}$ $55 \%$ among jute mill workers in West Bengal (India) ${ }^{26}$ and $15.5 \%$ among drivers of three-wheelers in Sri Lanka. ${ }^{27}$ In contrast, the prevalence rates are usually lower for industrialized countries, for example, USA $(10.2 \%)^{28}$ and Canada $(18.9 \%) .{ }^{29}$ However, in Germany, the point-prevalence was $37.1 \%, 76.0 \%$ for 1 -year prevalence and $85.5 \%$ for lifetime prevalence. ${ }^{30}$

Our findings also indicate that lower level of PA was independently associated with higher likelihood of experiencing back pain. However, the association was not even across sex and countries. For instance, the association between back pain and VPA was significant only in Pakistan and Sri Lanka, and among women but not men. In Bangladesh, no significant association was observed between back pain and engaging in PA of any form. However, lower frequency ( $<5$ days a week) of engaging in MPA appeared to be associated with increased likelihood of having back pain among both men and women in India. Though the association was significant in certain cases, it should be noted that these findings are not even for all the countries which indicates a differential association for different types of and back pain PA across sex and country. Current evidence regarding the association is inconclusive, mainly due to the heterogeneity in effect measures and the lack of uniformity in the definitions of back pain. ${ }^{31} \mathrm{~A} 6.5$-year follow-up study among Norwegian students reported a weak trend of decreasing LBP with MPA/high PA levels, but this association was not significant, and concluded that no clear relationship between PA and LBP was possible to establish among young adults. ${ }^{32} \mathrm{~A}$ recent literature review on the association between PA and LBP was also unable to determine if PA could have negative or positive effects on development of LBP in adults. ${ }^{33}$ However, our finding is consistent with one from the Netherlands which found positive effect of PA in the prevention of LBP among working population. ${ }^{34}$

As far as we are concerned, this is first study to report the prevalence of back pain and assess its relationship with PA among elderly people in South Asia. Sample size was considerably large and analysis followed rigorous standards. In addition to its contribution to the current literature, the findings of this study has several important implications for future researchers and for policy makers as well. Our results revealed a considerably high burden of back pain which should be taken into account when assessing overall health status of among the middle-aged to elderly population, and should be given due priority for further investigation on cause-specific management and rehabilitation. More population based studies are required to provide updated information on the prevalence of back pain and exploring the underlying causes, and impacts on health and well-being among the senior citizens. The ultimate goal will be to develop innovative ways to provide proper care, and offer a conducive environment and better support for patients living with chronic pain at large.

Apart from the contributions, the limitations of the current study should also be pointed out. First, as it was a crosssectional survey, the directionality of the association was not possible to determine. It is possible that back pain itself was the cause of low PA among the participants. The causality of the association needs to be verified by longitudinal studies. Also, the data on back pain and frequency of participating in PA were self-reported, and were not validated from independent sources. Therefore, the retrospective recalling suffers from the risk of reporting bias. We could not adjust the analysis for some important covariates such as presence of other disease conditions, medication use, and injury due to the secondary nature of the data.

\section{Conclusion}

In conclusion, our findings revealed that the prevalence of back pain was noticeably high among men and women aged 
$\geq 50$ years. Rate of participation in PA was also low. However, important differences were observe in the prevalence rates across countries. Given the advanced age of the subjects, it is understandable that participation in VPA and MPA cannot be regular. However, nonparticipation in regular walk is a matter of concern. The relationship between taking part in PA and back pain was consistent for some countries, but not other. Sex variation in the association was also remarkable. Further research is necessary to better understand the causality of this relationship.

\section{Acknowledgments}

We would like to thank WHO for providing the datasets used in this study. We also thank our colleagues who provided useful insights that helped the successful completion of the study.

\section{Authors' contributions}

GB was responsible for designing the study and collecting the datasets. Data analysis was performed by GB and ST. All authors contributed toward data analysis, drafting and revising the paper and agree to be accountable for all aspects of the work.

\section{Disclosure}

The authors report no conflicts of interest in this work.

\section{References}

1. Rebecca G, Saul B. A systematic review of the effects of exercise and physical activity on non-specific chronic low back pain. Healthcare (Basel). 2016;4(2):22.

2. Hoy D, March L, Brooks P, et al. The global burden of low back pain: estimates from the Global Burden of Disease 2010 study. Ann Rheum Dis. 2014;73(6):968-974.

3. Macfarlane GJ, Jones GT, Hannaford PC. Managing low back pain presenting to primary care: where do we go from here? Pain. 2006;122(3): 219-222.

4. Rodrigo D, Anaclaudia G, Neice MX. Prevalence of chronic low back pain: systematic review. Rev Saude Publica. 2015;49:1.

5. Antunes RS, de Macedo BG, Amaral Tda S, Gomes Hde A, Pereira LS, Rocha FL. Pain, kinesiophobia and quality of life in chronic low back pain and depression. Acta Ortop Bras. 2013;21(1):27-29.

6. Haggman S, Maher CG, Refshauge KM. Screening for symptoms of depression by physical therapists managing low back pain. Phys Ther. 2004;84(12):1157-1166.

7. Hurwitz EL, Morgenstern H, Yu F. Cross-sectional and longitudinal associations of low-back pain and related disability with psychological distress among patients enrolled in the UCLA Low-Back Pain Study. $J$ Clin Epidemiol. 2003;56(5):463-471.

8. Nyman T, Grooten WJ, Wiktorin C, Liwing J, Norrman L. Sickness absence and concurrent low back and neck-shoulder pain: results from the MUSIC-Norrtälje study. Eur Spine J. 2007;16(5):631-638.

9. Reme SE, Hagen EM, Eriksen HR. Expectations, perceptions, and physiotherapy predict prolonged sick leave in subacute low back pain. BMC Musculoskelet Disord. 2009;10:139.

10. Chien JJ, Bajwa ZH. What is mechanical back pain and how best to treat it? Curr Pain Headache Rep. 2008;12(6):406-411.

11. Atlas SJ, Deyo RA. Evaluating and managing acute low back pain in the primary care setting. J Gen Intern Med. 2001;16(2):120-131.
12. Woolf AD, Pfleger B. Burden of major musculoskeletal conditions. Bull World Health Organ. 2003;81(9):646-656.

13. Bekkering GE, Hendriks HJ, Koes BW, et al. Dutch physiotherapy guidelines for low back pain. Physiotherapy. 2003;89(2):82-96.

14. Hayden JA, van Tulder MW, Tomlinson G. Systematic review: strategies for using exercise therapy to improve outcomes in chronic low back pain. Ann Intern Med. 2005;142(9):776-785.

15. Dreisinger TE. Exercise in the management of chronic back pain. Ochsner J. 2014;14(1):101-107.

16. Little P, Smith L, Cantrell T, Chapman J, Langridge J, Pickering R. General practitioners' management of acute back pain: a survey of reported practice compared with clinical guidelines. BMJ. 1996;312(7029): 485-488.

17. Hoy D, Brooks P, Blyth F, Buchbinder R. The Epidemiology of low back pain. Best Pract Res Clin Rheumatol. 2010;24(6):769-781.

18. Rainville J, Hartigan C, Martinez E, Limke J, Jouve C, Finno M. Exercise as a treatment for chronic low back pain. Spine J. 2004;4(1): 106-115.

19. Bishwajit G, Daniel Peter O’Leary, Ghosh S, Sanni Y, Shangfeng T, Zhanchun F. Association between depression and fruit and vegetable consumption among adults in South Asia. BMC Psychiatry. 2017;17:15.

20. World Health Organization. World Report on Disability 2011. Geneva, Switzerland: World Health Organization; 2011.

21. Elders LA, Burdorf A. Prevalence, incidence, and recurrence of low back pain in scaffolders during a 3-year follow-up study. Spine. 2004;29(6):E101-E106.

22. Hagen KB, Tambs K, Bjerkedal T. A prospective cohort study of risk factors for disability retirement because of back pain in the general working population. Spine (Phila Pa 1976). 2002;27(16):1790-1796.

23. Bhattarai S, Chhetri HP, Alam K, Thapa P. A study on factors affecting low back pain and safety and efficacy of NSAIDs in acute low back pain in a tertiary care hospital of Western Nepal. J Clin Diagn Res. 2013; $7(12): 2752-2758$.

24. World Health Organization. Global Health Risks: Mortality and Burden of Disease Attributable to Selected Major Risks. Geneva, Switzerland: World Health Organization; 2009.

25. Sharma SC, Singh R, Sharma AK, Mittal R. Incidence of low back pain in workage adults in rural North India. Indian J Med Sci. 2003;57(4): $145-147$.

26. Goswami S, Dasgupta S, Samanta A, et al. Load handling and repetitive movements are associated with chronic low back pain among Jute Mill Workers in India. Pain Res Treat. 2016;2016:7843216.

27. Noda M, Malhotra R, DeSilva V, et al. Occupational risk factors for low back pain among drivers of three-wheelers in Sri Lanka. Int J Occup Environ Health. 2015;21(3):216-222.

28. Freburger JK, Holmes GM, Agans RP, et al. The rising prevalence of chronic low back pain. Arch Intern Med. 2009;169(3):251-258.

29. Schopflocher D, Taenzer P, Jovey R. The prevalence of chronic pain in Canada. Pain Res Manag. 2011;16(6):445-450.

30. Schmidt CO, Raspe H, Pfingsten M, et al. Back pain in the German adult population: prevalence, severity, and sociodemographic correlates in a multiregional survey. Spine (Phila Pa 1976). 2007;15;32(18): 2005-2011.

31. Hamberg-van Reenen HH, Ariëns GA, Blatter BM, van Mechelen W, Bongers PM. A systematic review of the relation between physical capacity and future low back and neck/shoulder pain. Pain. 2007;130(1-2): 93-107.

32. Lunde LK, Koch M, Hanvold TN, Wærsted M, Veiersted KB. Veiersted. Low back pain and physical activity - A 6.5 year follow-up among young adults in their transition from school to working life. BMC Public Health. 2015;15:1115.

33. Heneweer H, Staes F, Aufdemkampe G, van Rijn M, Vanhees L. Physical activity and low back pain: a systematic review of recent literature. Eur Spine J. 2011;20(6):826-845.

34. Heneweer H, Picavet HS, Staes F, Kiers H, Vanhees L. Physical fitness, rather than self-reported physical activities, is more strongly associated with low back pain: evidence from a working population. Eur Spine J. 2012; 21(7): 1265-1272. 
The Journal of Pain Research is an international, peer reviewed, open access, online journal that welcomes laboratory and clinical findings in the fields of pain research and the prevention and management of pain. Original research, reviews, symposium reports, hypothesis formation and commentaries are all considered for publication
The manuscript management system is completely online and includes a very quick and fair peer-review system, which is all easy to use. Visit http://www.dovepress.com/testimonials.php to read real quotes from published authors. 